\title{
ORIGIN OF BOTH GREAT VESSELS FROM THE RIGHT VENTRICLE WITHOUT PULMONARY STENOSIS*
}

\author{
BY \\ HENRY N. NEUFELD, RUSSELL V. LUCAS, JR., RICHARD G. LESTER, PAUL \\ ADAMS, JR., RAY C. ANDERSON, AND JESSE E. EDWARDS \\ From the Departments of Radiology, Pediatrics and Pathology, University of Minnesota, Minneapolis, and the \\ Department of Pathology, the Charles T. Miller Hospital, St. Paul, Minnesota, U.S.A. \\ Received October 10, 1961
}

In a recent communication Neufeld and associates (1961) described the pathological, functional, electrocardiographic, and clinical findings in a group of eight cases of an uncommon condition in which both great vessels arose from the right ventricle in the absence of pulmonary stenosis. In seven of the eight cases of this condition (for which such synonyms as "partial transposition," "Taussig-Bing complex," "double outlet right ventricle" have been offered) the picture both hæmodynamically and clinically resembled that in large ventricular septal defects.

One of the patients (Case 4) of the earlier report, which emanated from the Mayo Clinic, presented somewhat different features from the remaining seven and resembled not only the case reported by Taussig and Bing (1949) but also others reported later as examples of the so-called Taussig-Bing complex. Distinguishing features of the latter type of case included cyanosis and higher levels of oxygen saturation of blood in the pulmonary artery than in a systemic artery or the aorta.

This difference in groups of patients having apparently similar anatomical findings (that is, origin of both great vessels from the right ventricle without pulmonary stenosis) prompted a review of another series represented by ten cases from the University of Minnesota Hospitals. From this material a report of correlative studies of the anatomical findings with clinical, hæmodynamic, and angiocardiographic findings represents the main purpose of this communication.

These studies suggest the value of classifying into two subdivisions the cases manifesting origin of both great vessels from the right ventricle without pulmonary stenosis. Furthermore, we believe, on the basis of the evidence we shall present, that the so-called Taussig-Bing complex represents one of these two subdivisions. Nine of the ten patients with the anomaly came to necropsy, while the tenth (Case 9), later to be classified as an example of Type IIA, was studied only clinically. The anatomical similarities in all cases of origin of both great vessels from the right ventricle regardless of subdivision are as follows.

1. The pulmonary trunk and aorta are normally related externally.

2. The aorta originates entirely from the right ventricle lying to the right of the pulmonary trunk.

3. The aortic valve lies higher than normal and is located at about the same cross-sectional and coronal body planes as the pulmonary valve.

4. Discontinuity of mitral and aortic valvular tissue is the usual finding (in seven of nine cases in the current study). In the nine examples of the malformation for which necropsy specimens are

* This study was supported in part by Research Grant H 5694 of the National Heart Institute, National Institutes of Health United States Public Health Service. 
available, anatomical differences could be recognized, depending on whether the universally present ventricular septal defect was anatomically remote from or closely related to one or both of the semilunar valves. Using this criterion, we were able to assign each of the nine cases to one of two major types, according to the following classification.

\section{Classification}

Type I. Origin of both great vessels from the right ventricle without pulmonary stenosis; ventricular septal defect below the crista supraventricularis.

Six examples represented this type, in which the only outlet for the left ventricle was a ventricular septal defect that opened into the right ventricle beneath the crista supraventricularis and, in particular, beneath the parietal band of this structure (Fig. 1A).

Type II. Origin of both great vessels from the right ventricle without pulmonary stenosis; ventricular septal defect above the crista supraventricularis.

There were three examples of this type, in which the defect lay above the crista supraventricularis. In two in which the heart was examined at necropsy, the ventricular septal defect was observed to be closely related to the pulmonary valve only; these two, sub-classified as Type IIA (Fig. 1B), appeared to be examples of the malformation commonly known as the Taussig-Bing complex. The third differed from these first two in two respects: (1) the ventricular septal defect, while lying
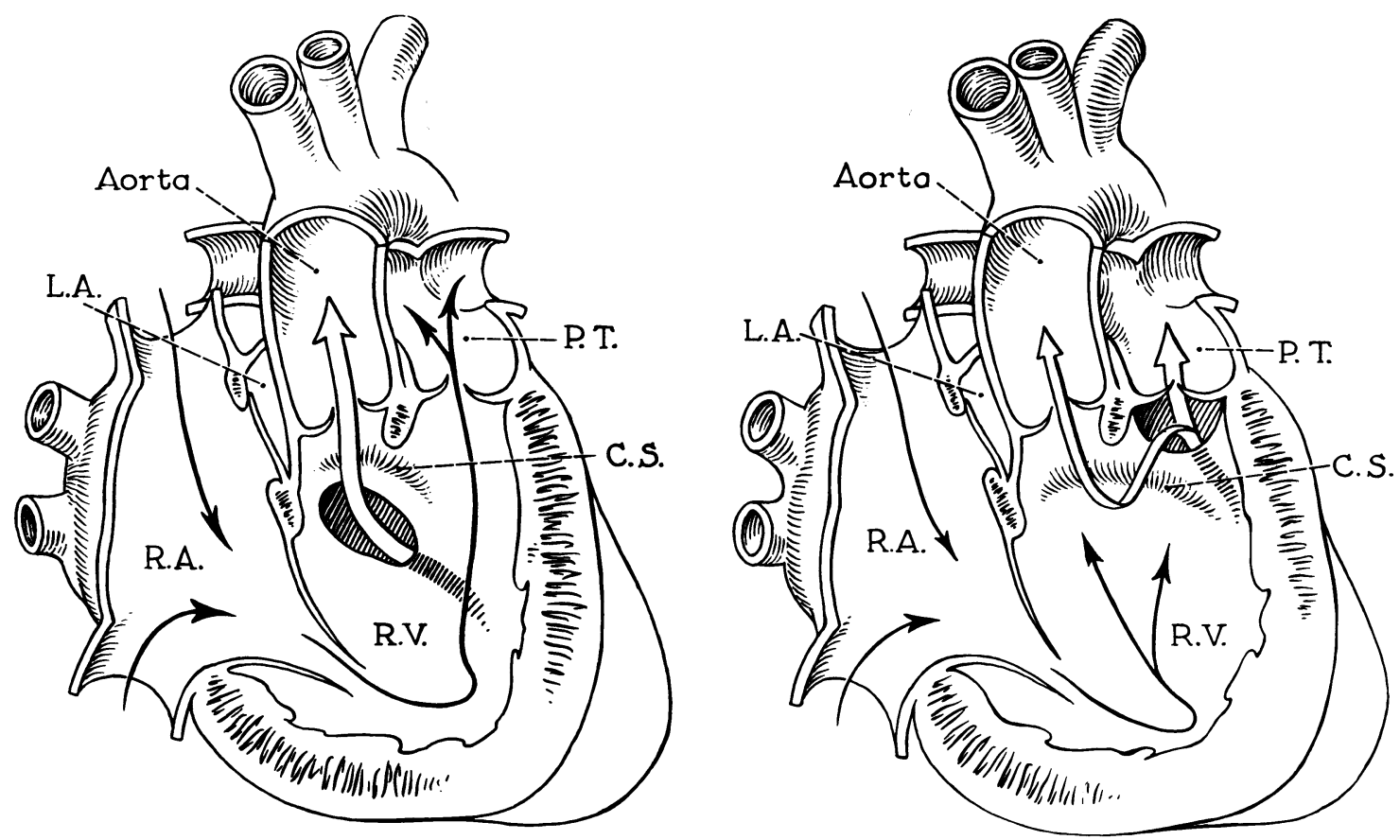

FIG. 1.-Left. Diagrammatic representation of origin of both great vessels from right ventricle, Type I. The specific anatomical feature is that the ventricular septal defect lies postero-inferior to the crista supraventricularis and that the direction of the stream from the left ventricle appears to proceed predominantly to the aorta. The two semilunar valves lie at about the same body plane with the aortic valve to the right of the pulmonary valve.

Right. Diagrammatic representation of origin of both great vessels from right ventricle without pulmonary stenosis, Type IIA (Taussig-Bing complex). The distinguishing feature is that the ventricular septal defect lies above the crista supraventricularis and in close apposition to the pulmonary valve. In contrast to the situation in Type I, the left ventricular output appears to be more readily direct to the pulmonary trunk than to the aorta. As in Type I the two semilunar valves lie at the same body plane and the aortic valve to the right of the pulmonary valve. 
above the crista supraventricularis, involved a more extensive area than in Type IIA; and (2) this defect was closely related not only to the pulmonary valve but also to the transposed aortic valve. This subtype is called Type IIB.

\section{Pathological Findings}

Type I: Origin of both great vessels from the right ventricle without pulmonary stenosis; ventricular septal defect below the crista supraventricularis.

Six patients were found to have this type of anomaly. The relationship of the great vessels was similar in each of the six. The aorta and pulmonary trunk had a normal external appearance, the ascending aorta lying to the right of the pulmonary trunk (Fig. 2). The internal relationships of

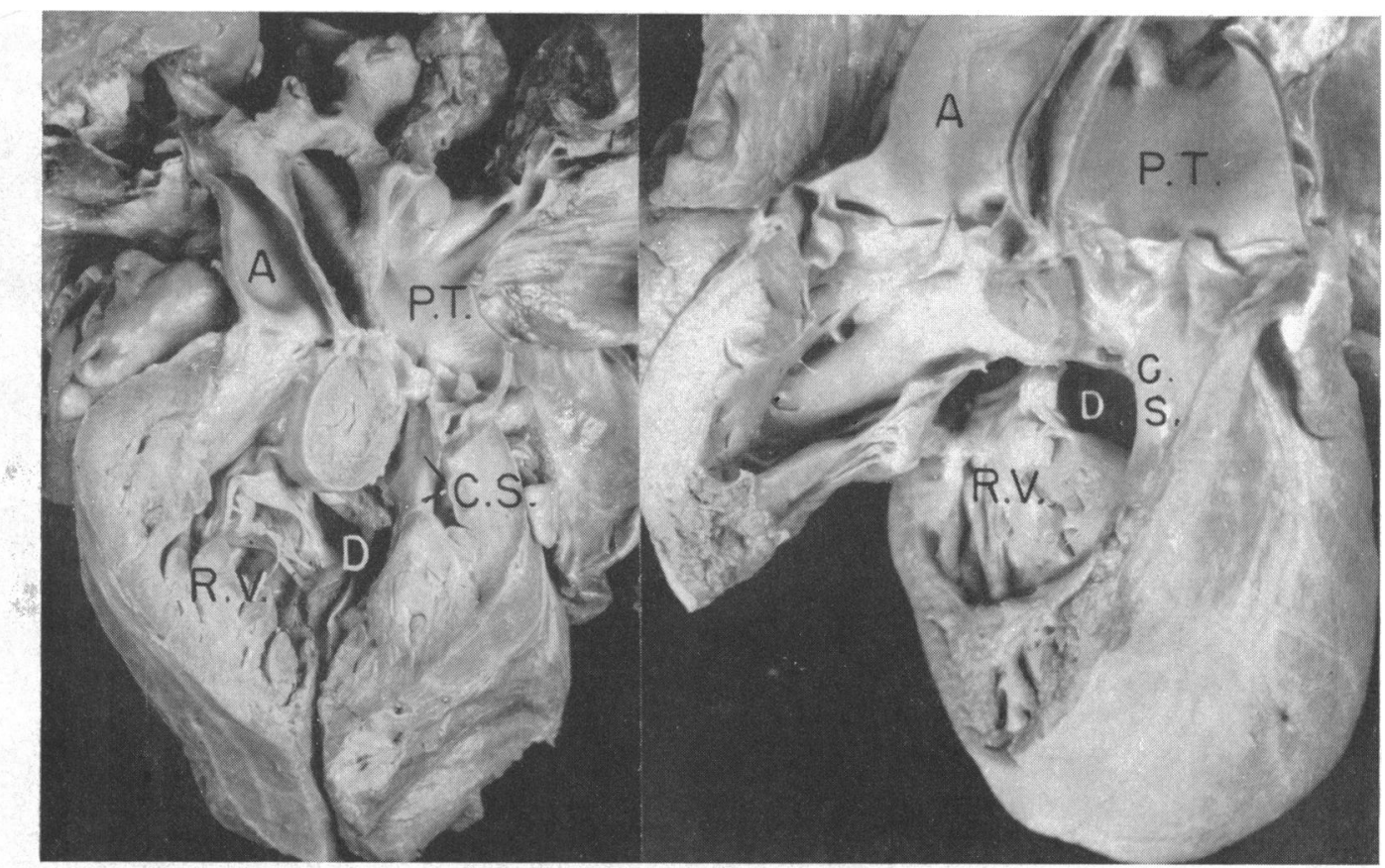

FIG. 2.-Origin of both great vessels from right ventricle without pulmonary stenosis, Type I. View of great vessels and right ventricle. Left: Case 1. The right ventricle has been opened as have been the aorta and the pulmonary trunk. The ventricular septal defect (D) lies postero-inferior to the crista supraventricularis (C. S.), which separates the defect from the semilunar valves. $A=$ aorta; P.T.=pulmonary trunk; R.V.=right ventricle. The aortic valve lies to the right of and at the same body plane as the pulmonary valve.

Right: Case 4. A sagittal section has been made through the right ventricle and the two great vessels arising from it. Abbreviations as in Left. The ventricular septal defect is separated from each semilunar valve and the relationship of the two semilunar valves is brought out. From the exterior the ascending aorta appears to be in a normal position. The aorta stops abruptly at the right ventricular level rather than proceeding downward and to the left to make normal continuity with the left ventricle. In each instance illustrated there is no continuity between atrioventricular valvular tissue and semilunar valvular tissue.

the great vessels, however, were grossly abnormal. The aorta did not extend from the base of the heart to the left of and behind the pulmonary trunk to a position of normal origin from the left ventricle; instead it originated entirely from the right ventricle. The aortic valve lay to the right of, and in the same coronal body plane as, the pulmonary valve (Fig. 2). The aortic orifice occupied a position above the posterior aspect of the parietal limb of the crista supraventricularis and in front of the tricuspid valve (Fig. 2). 
In each of the six patients a ventricular septal defect was located below the crista supraventricularis, which formed the superior and anterior margin of the defect. The junction of the anterior mitral leaflet and the septal tricuspid leaflet formed the posterior boundary of the defect. When viewed from the left ventricular side, the defect included the area of the membranous septum and was the only outlet for the left ventricle (Fig. 3). In four patients (Cases 1, 3, 4, and 6) the defect

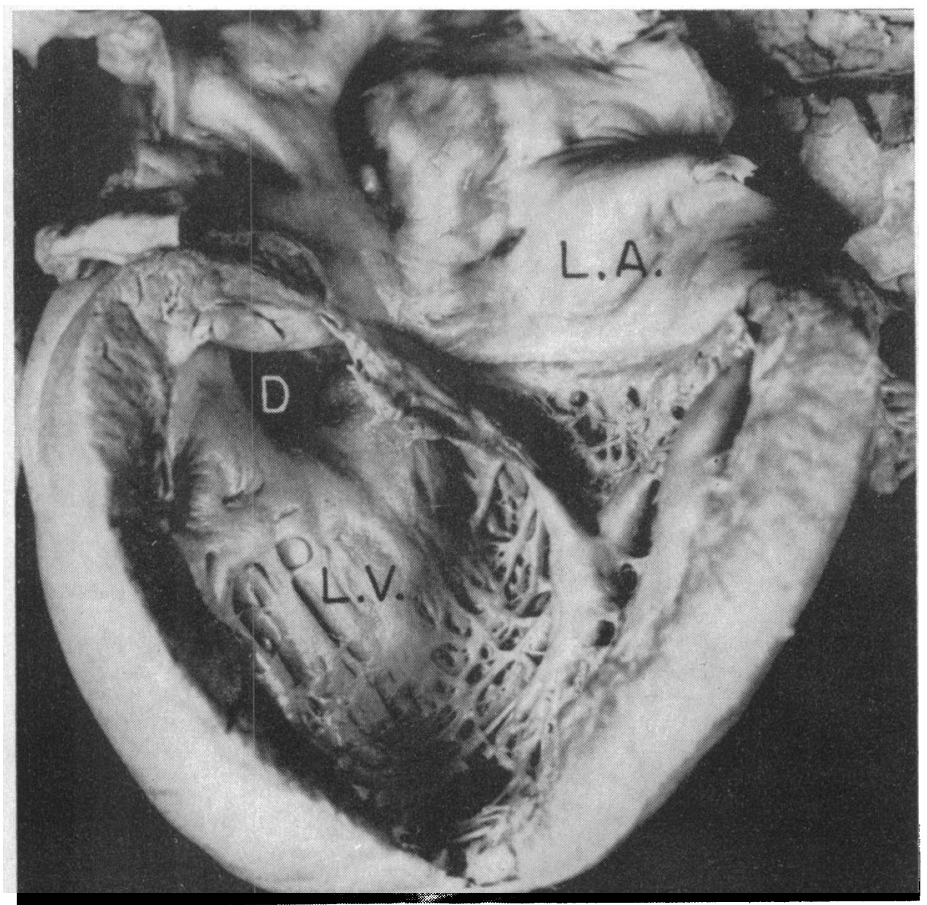

Fig. 3.-Case 7. Origin of both great vessels from right ventricle without pulmonary stenosis, Type IIA. Left side of heart. The left atrium (L.A.) makes normal connection with the left ventricle (L.V.). The only outlet for the left ventricle is the ventricular septal defect (D). Through the latter, left ventricular blood is carried into the right ventricle. Aorta does not appear in illustration. This specimen is from an example of Type II but portrays equally the left ventricular relationships seen in the Type $I$ form.

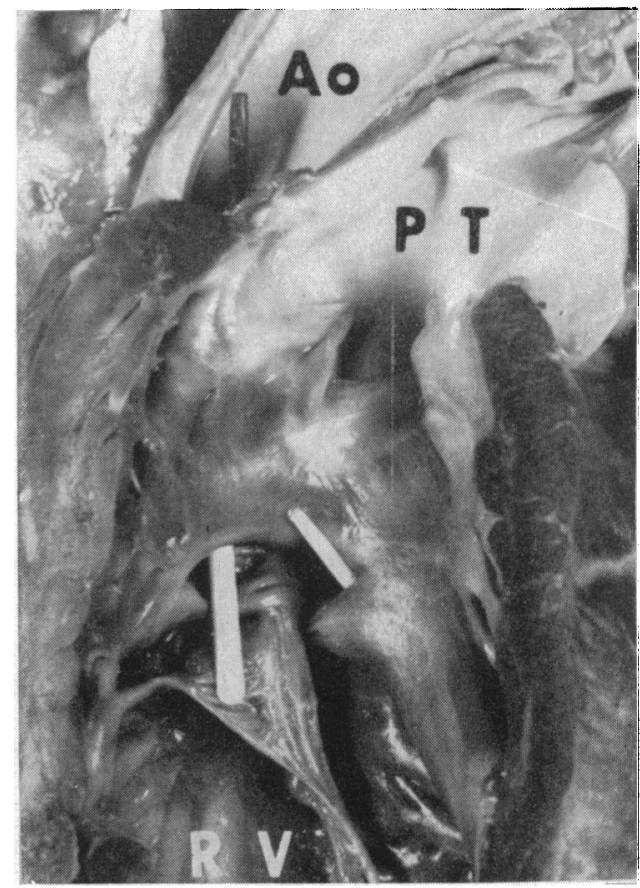

Fig. 4.- Case 5. Origin of both great vessels fror right ventricle without pulmonary stenosis Type I. Details of interrelationships betwee: right ventricular aspect of ventricular septc defect and origin of both great vessels. Th right-hand probe lies in the ventricular septc defect and is separated from the pulmonar valve by the crista supraventricularis. Th left-hand probe passes posterior to the parietc band of the crista supraventricularis an appears in the aorta (Ao). P.T.=pulmonar trunk; R.V.=right ventricle.

was "large" (greater than $1 \mathrm{~cm}$. per sq. m. of body surface area). It was smaller in the two other patients, being $5 \mathrm{~mm}$. in diameter in Case 2 and $2 \mathrm{~mm}$. in Case 5 (Fig. 4). The small size of the ventricular septal defect in these two could conceivably have formed an obstruction to outflow from the left ventricle.

In the normal heart, the anterior leaflet of the mitral valve is continuous with aortic valvular tissue. By contrast, in five of the six cases classified in the Type I subdivision of the malformation, no continuity existed between these valvular elements. The anterior leaflet of the mitral valve was separated from aortic valvular tissue by a muscular mass (Fig. 2). Only in Case 6 was the anterior leaflet of the mitral valve continuous with the aortic valve. Here the anterior leaflet of the mitral valve was unusually long and extended through the ventricular septal defect to remain continuous with the aortic valve. 
Of the six cases representing Type I, three (Cases 1, 2, and 3) presented no associated cardiac anomalies. In one (Case 4), coarctation of the aorta was associated. Another (Case 5) exhibited an abnormality at the mitral valve represented by focal displacement of the valve downward into the left ventricle. This displacement occurred along a line about $1 \mathrm{~cm}$. below the mitral annulus in a manner resembling the tricuspid valve in Ebstein's malformation. In addition, the mitral valve was thickened and grossly deformed and it projected into the cavity of the left ventricle. As a result the effective volume of the left ventricle was reduced (Fig. 5). In the sixth (Case 6) a supravalvular stenosing ring in the left atrium above the mitral valve was noted; this lesion has been illustrated in a previous paper describing this case (Manubens et al., 1960).

Type II: Origin of both great vessels from the right ventricle without pulmonary stenosis; ventricular septal defect above the crista supraventricularis.

Type IIA: Ventricular septal defect under the pulmonary valve.

The relationship of the great vessels in two patients seen at necropsy (Cases 7 and 8) was essentially like that seen in the previous group classified as Type I (Fig. 6). The ventricular septal defect was "large" in each case. The point of difference lay in the position of the ventricular septal defect which was located above instead of below the crista

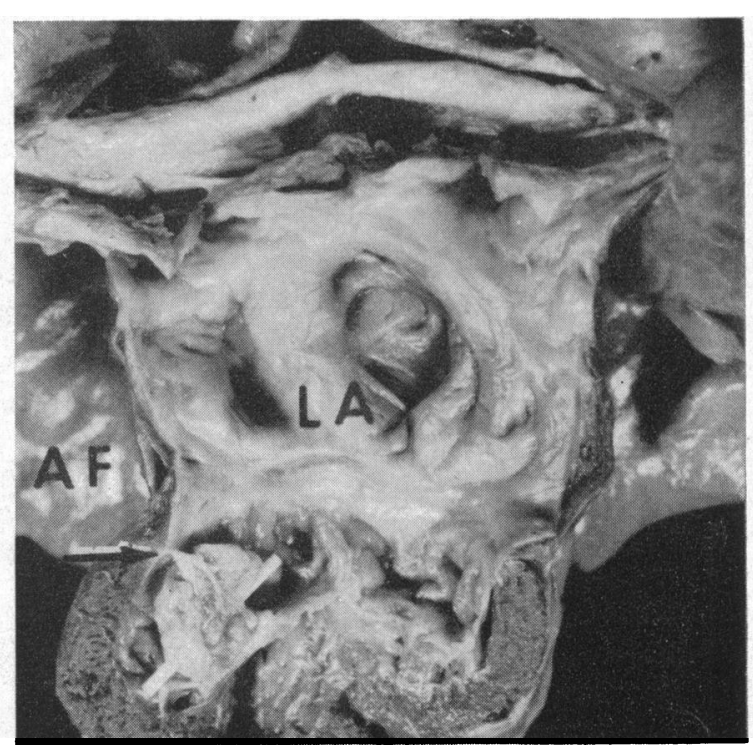

FIG. 5.-Case 5. Origin of both great vessels from right ventricle without pulmonary stenosis, Type I. Illustration to show an unusual and associated malformation of the mitral valve. Left side of heart is illustrated. The left atrium (L.A.) is hypertrophied and moderately dilated. Communicating with the left ventricle (L.V.) is an anomalous mitral valve. This has the shape of a funnel. The probe lies at the base of the funnel and extends through its apex into the left ventricle. The basal attachment of the mitral valve is partially anomalous. At the arrow the attachment is considerably below the level of the annulus fibrosis (A.F.). This anomaly of the mitral valve may be identified as an Ebstein-like malformation of the mitral valve. It is of interest that this type of malformation of the left atrioventricular valve when present, is usually associated with corrected transposition of the great vessels. Absence of the latter malformation in this case makes this anomaly of the mitral valve particularly unusual. supraventricularis (Fig. 2, right and Fig. 7).

The upper margin of the defect was formed by pulmonary valvular tissue, the left lateral margin by the parietal band of the crista supraventricularis, the inferior margin by the muscular septum, and the right lateral margin by a muscle mass separating the orifice of the pulmonary valve from the aortic valve. Thus, in these cases the ventricular septal defect lay close to the pulmonary valve and was anatomically separated from the aortic valve by the aforementioned mass of muscular tissue.

In these patients no continuity existed between the anterior leaflet of the mitral valve and aortic valvular tissue. Coarctation of the aorta and a patent ductus arteriosus were evident in both. The third patient in this category (Case 9) was the subject only of clinical study.

\section{Type IIB: Ventricular septal defect under the pulmonary and transposed aortic valves}

The relationship of the great vessels in the one patient in this subgroup of Type II (Case 10) was identical with that found in the previous two categories described. The ventricular septal defect lay above the crista supraventricularis and was "large" (greater than $1 \mathrm{~cm}$. per sq. m. of body surface area). In contrast to the situation in Type IIA, the upper margin of the defect was formed not only by the pulmonary valve but also by part of the aortic valve (Fig. 8). The 


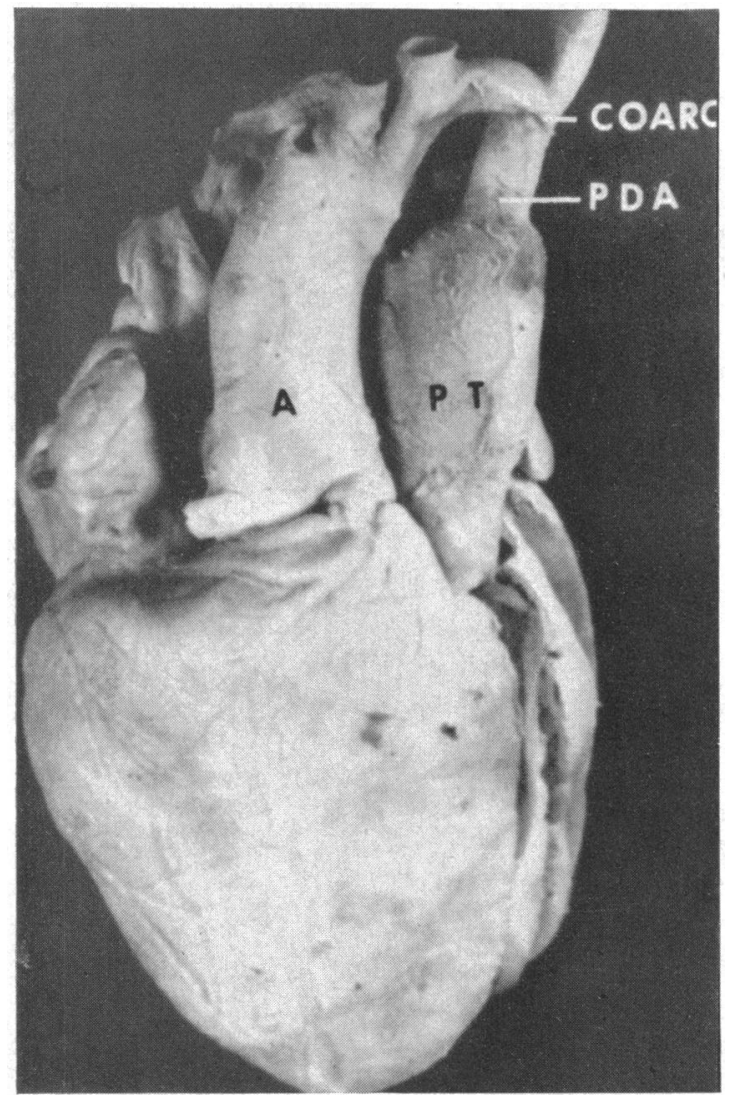

Fig. 6.-Case 8. Origin of both great vessels from right ventricle without pulmonary stenosis, Type IIA. External view of the heart and great vessels viewed slightly from the right. The ascending aorta lies to the right of the pulmonary trunk having an essentially normal position. The abnormality of the aorta resides not in its external appearance but in its failure to connect with the left ventricle. Associated patent ductus arteriosus (PDA) and coarctation of the aorta (Coarc) illustrated. These anomalies are not uncommon in origin of both great vessels from the right ventricle whether Type I or Type II.

enlongated anterior leaflet of the mitral valve was anatomically continuous with the aortic valvular tissue. Coarctation of the aorta had been repaired some time before this patient died.

\section{Clinical Features}

The clinical and electrocardiographic findings in the ten patients of this study are summarized in Table I. In the text, we shall consider first the clinical findings according to the foregoing anatomical subdivisions, and then review the electrocardiographic findings.

Type I. The ages of the six patients in whom the anatomical features conformed in Type I (Cases 1-6) ranged from three months to nineteen years. Five of them were male. 


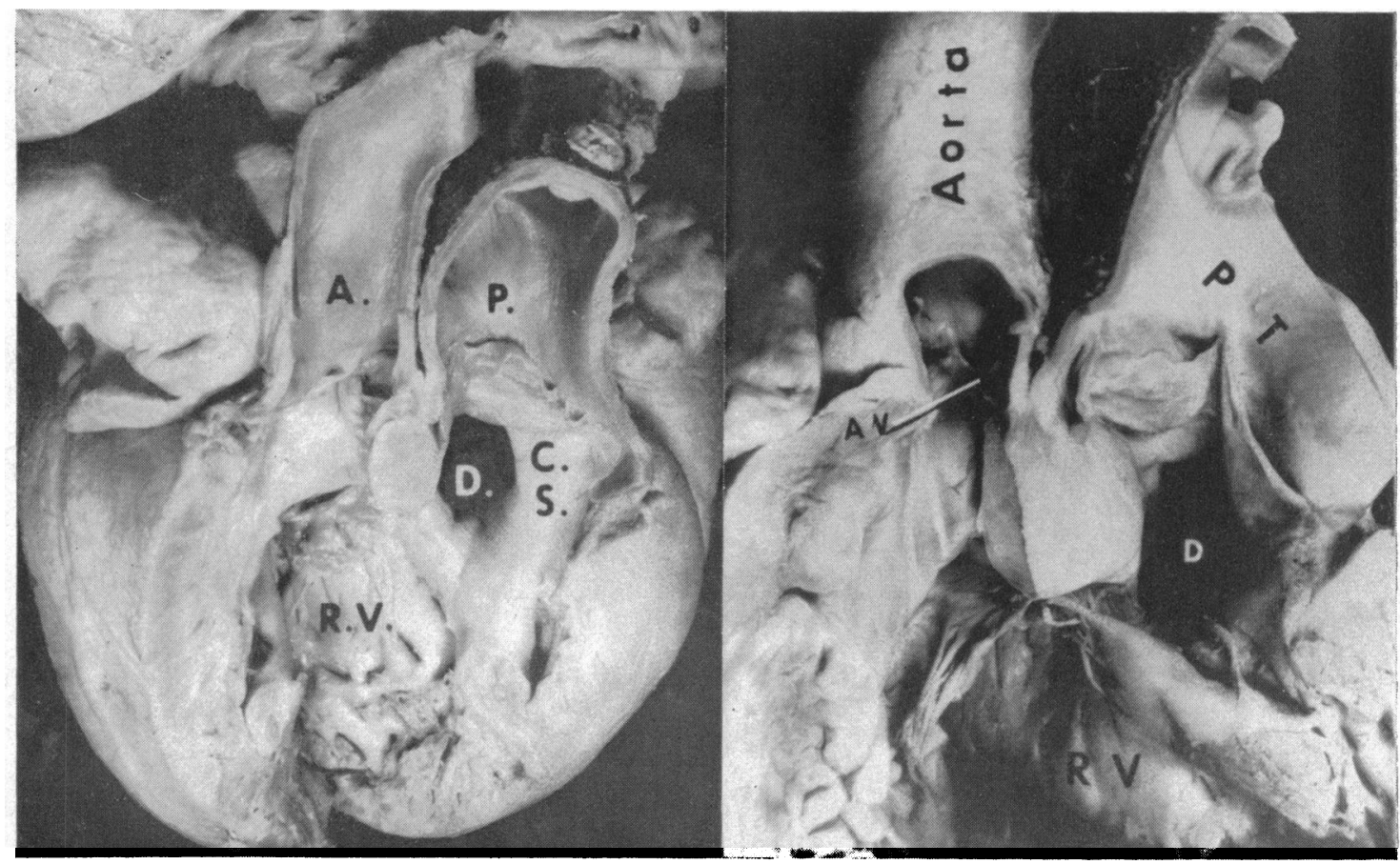

FIG. 7.-Origin of both great vessels from right ventricle without pulmonary stenosis, Type IIA. Interrelationships of right ventricle, ventricular septal defect, and origin of great vessels. Left: Case 7. The interior of the right ventricle (R.V.) has been exposed. The ventricular septal defect (D) lies above the crista supraventricularis (C.S.) and in direct apposition to the pulmonary valve. $\mathrm{P}=$ pulmonary trunk. The aortic valve which lies at the same body level as and to the right of the pulmonary valve is separated from the ventricular septal defect by a mass of muscle. Right: Case 8. The interior of the outflow portion of the right ventricle (R.V.) has been exposed showing the large ventricular septal defect (D). The latter lies above the crista supraventricularis and in close apposition to the valve of the pulmonary trunk (P). The aortic valve (AV) lies to the right of the pulmonary trunk and is separated from the ventricular septal defect by a mass of muscle. Aorta=ascending aorta.

Cyanosis was manifested in only two instances (Cases 4 and 5) and in each it was mild in degree. An additional malformation was present in each of these two; in one (Case 4) this took the form of coarctation of the aorta and in the other (Case 5) the Ebstein-like malformation of the mitral valve already described.

Congestive cardiac failure was present in all six patients and was the cause of death in four. In the two whose ventricular septal defects were surgically treated (Cases 2 and 4), an artificial tunnel was created from the left ventricle to the aorta (Cases 3 and 6). Although this appears to be the appropriate procedure for this condition, both patients died during the early post-operative period.

In each of the six patients physical examination showed a systolic murmur, ranging from Grade II and Grade IV, with maximum intensity universally at the third or fourth left intercostal spaces. The murmur was undistinguishable in nature and location from the systolic murmur usually present in patients with ventricular septal defect. One nineteen-year-old patient (Case 3), the oldest in the present series, had a diastolic murmur of the Graham-Steele type, which followed an accentuated second sound at the pulmonary area.

Values for systemic blood pressure reflected the associated coarctation of the aorta in one patient (Case 4) and were normal in the remainder.

Type II. It will be recalled that among the 10 cases of origin of both great vessels from the right ventricle three (Cases 7, 8, and 9) were classified anatomically as representing Type IIA, and one (Case 10) as Type B, the ventricular septal defect lying not only immediately beneath the 
TABLE I

Clinical and Electrocardiographic Findings in Ten Cases of Origin of Both Great Vessels from the Right Ventricle Without Pulmonary Stenosis

\begin{tabular}{|c|c|c|c|c|c|c|c|c|c|c|c|c|c|}
\hline \multirow{3}{*}{$\begin{array}{l}\text { Case } \\
\text { No. }\end{array}$} & \multicolumn{4}{|c|}{ Clinical findings } & \multicolumn{9}{|c|}{ Electrocardiographic findings } \\
\hline & \multirow{2}{*}{ Sex } & \multirow{2}{*}{$\begin{array}{r}\text { Age at } \\
\text { death }\end{array}$} & \multirow{2}{*}{ Cyanosis } & \multirow{2}{*}{$\begin{array}{l}\text { Cardiac } \\
\text { murmur }\end{array}$} & \multirow{2}{*}{$P$ waves } & \multirow{2}{*}{$\begin{array}{l}\text { P-R } \\
\text { inter- } \\
\text { val in } \\
\text { sec. }\end{array}$} & \multirow{2}{*}{$\begin{array}{l}\text { Elec. } \\
\text { axis } \\
\text { of QRS }\end{array}$} & \multirow{2}{*}{$\begin{array}{l}\text { Vector } \\
\text { loop } \\
\text { (F.P.) }\end{array}$} & \multicolumn{2}{|c|}{$\mathrm{V} 1 \mathrm{in} \mathrm{mm}}$. & \multicolumn{3}{|c|}{ V6 in $\mathrm{mm}}$. \\
\hline & & & & & & & & & $\mathbf{R}$ & $\mathbf{S}$ & $\mathbf{Q}$ & $\mathbf{R}$ & $\mathbf{S}$ \\
\hline
\end{tabular}

Type I

\begin{tabular}{|c|c|c|c|c|c|c|c|c|c|c|c|c|c|}
\hline 1 & $\mathbf{M}$ & $12 \mathrm{mo}$. & No & $\begin{array}{c}2 / 6 \\
\text { 3rd LICS }\end{array}$ & Normal & $0 \cdot 13$ & $+60^{\circ}$ & $\mathrm{Cl}$. & 7 & 10 & 2 & 11 & 2 \\
\hline 2 & $\mathbf{M}$ & $121 / 2 \mathrm{mo}$ & No & $\begin{array}{c}2 / 6 \\
\text { 3rd LICS }\end{array}$ & $\begin{array}{l}\text { Peaked } \\
\text { in lead } \\
\text { II }\end{array}$ & $0 \cdot 16$ & $+60^{\circ}$ & $\mathrm{Cl}$. & 10 & 50 & 2 & 22 & 11 \\
\hline 3 & $\mathbf{M}$ & $19 \mathrm{yr}$. & No & $\begin{array}{c}3 / 6^{*} \\
\text { 3rd and } \\
\text { 4th LICS }\end{array}$ & Normal & 0.21 & $+60^{\circ}$ & C. $\mathrm{Cl}$. & 15 & 1 & 6 & 24 & 3 \\
\hline 4 & $\mathbf{M}$ & $31 / 2 \mathrm{mo}$ & $\begin{array}{c}3+ \\
\text { Birth }\end{array}$ & $\begin{array}{c}3 / 6 \\
\text { 4th LICS } \\
\end{array}$ & Normal & $0 \cdot 16$ & $-60^{\circ}$ & C. $\mathrm{Cl}$. & 16 & 4 & - & 9 & 9 \\
\hline 5 & $\mathbf{M}$ & $3 \mathrm{mo}$. & $\begin{array}{c}2+ \\
\text { Birth }\end{array}$ & $\begin{array}{c}2 / 6 \\
\text { 3rd LICS } \\
\end{array}$ & Normal & 0.19 & $+60^{\circ}$ & $\mathrm{Cl}$. & 14 & 2 & - & $\overline{10}$ & 10 \\
\hline 6 & $\mathbf{F}$ & 2 yr. & No & $\begin{array}{c}4 / 6 \\
\text { 4th LICS }\end{array}$ & $\begin{array}{l}\text { Peaked } \\
\text { in II, } \\
\text { III } \\
\text { AVF } \\
\end{array}$ & 0.15 & $-70^{\circ}$ & C. $\mathrm{Cl}$. & 18 & 4 & 0.5 & 13 & 22 \\
\hline
\end{tabular}

Type IIA

\begin{tabular}{|c|c|c|c|c|c|c|c|c|c|c|c|c|c|}
\hline 7 & $\mathbf{F}$ & 3 wk. & $\begin{array}{c}2+ \\
1 \mathrm{wk} .\end{array}$ & $\begin{array}{c}3 / 6 \\
\text { 3rd LICS }\end{array}$ & Normal & $0 \cdot 17$ & $+110^{\circ}$ & Cl. & 3 & 6 & 3 & 10 & - \\
\hline 8 & $\mathbf{M}$ & $14 \mathrm{mo}$. & $\underset{\text { Birth }}{2+}$ & $\begin{array}{c}3 / 6 \\
\text { 3rd LICS }\end{array}$ & $\begin{array}{l}\text { Peaked } \\
\text { in I, II, } \\
\text { III, } \\
\text { AVF, } \\
\text { V1 }\end{array}$ & $0 \cdot 16$ & $+130^{\circ}$ & $\mathrm{Cl}$. & 17 & 5 & 2 & 11 & 8 \\
\hline 9 & $\mathbf{M}$ & $3 \mathrm{mo} . \dagger$ & $\underset{\text { Birth }}{2+}$ & $\begin{array}{c}2-3 / 6 \\
\text { 4th LICS }\end{array}$ & $\begin{array}{l}\text { Peaked } \\
\text { in I, II, } \\
\text { AVF, } \\
\text { V1, V2, } \\
\text { V3 }\end{array}$ & $0 \cdot 14$ & $+120^{\circ}$ & $\mathrm{Cl}$. & $\begin{array}{l}Q=5 \\
R=10\end{array}$ & - & - & 22 & 25 \\
\hline
\end{tabular}

Type IIB

\begin{tabular}{l|l|l|c|c|c|c|c|c|c|c|c|c|c}
\hline 10 & F & $41 / 2$ yr. & $\begin{array}{c}2+ \\
\text { Birth }\end{array}$ & $\begin{array}{c}2-3 / 6 \\
\text { 4th LICS }\end{array}$ & Normal & $0 \cdot 16$ & $+120^{\circ}$ & Cl. & 13 & - & 1 & 15 & 4 \\
\hline
\end{tabular}

* Also Graham-Steele diastolic murmur.

C. $\mathrm{Cl}$. = Counterclockwise.

LICS $=$ Left intercostal space.
F.P. $=$ Frontal plane.

$\dagger=$ Living patient.

$\mathrm{Cl} .=$ Clockwise. 
pulmonary valve but also in part beneath the aortic valve.

The clinical features among the four cases of Type II were similar regardless of subtypes. Their ages ranged from three weeks to four and a half years, one patient (Case 9) having survived banding of the pulmonary artery at the age of three months. Two were male and two female. In each of the three patients with the Type IIA malformation (Cases 7, 8, and 9) cyanosis was noted continuously from the time of birth and in the one with the Type IIB malformation (Case 10) cyanosis was continuous from the age of two years. In each of the four patients with the Type II malformation a systolic murmur was present, indistinguishable in nature from the type of murmur noted in the usual large ventricular septal defect.

\section{ELECTROCARDIOGRAPHIC FeATURES}

(TABLE I)

Type I. The six patients with the Type I anomaly each showed sinus rhythm. The $P-R$ interval was prolonged in one and normal in five. Tall and notched $P$ waves in leads II and V1 were noted in two instances (Cases 2 and 5). One of these (Case 2) had a very small ventricular septal defect which obstructed the flow from the left ventricle: this obstruction was associated with elevation of the left ventricular end-diastolic pressure $(15 \mathrm{~mm} . \mathrm{Hg})$. The other (Case 5) exhibited the Ebstein-like malformation of the mitral valve already described. The pressure in

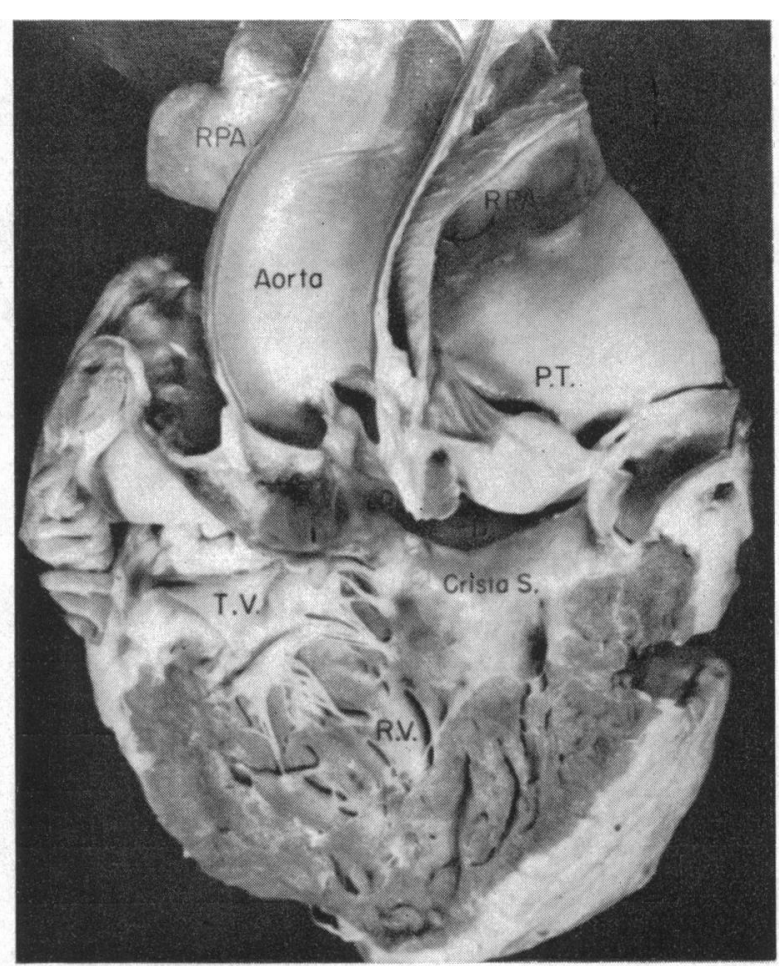

FIG. 8.-Case 10. Origin of both great vessels from right ventricle without pulmonary stenosis, Type IIB. The anterior wall of the right ventricle has been removed exposing the septal wall of this chamber (R.V.). A portion of the tricuspid valve (T.V.) is in the illustration. The ventricular septal defect (D) lies under the entire pulmonary valve and extends for a short distance under the nearby aortic valve. In contradistinction to the situation in Type IIA wherein the ventricular septal defect is closely applied only to the pulmonary valve, the relationship in Type IIB is that the defect is closely related not only to the pulmonary valve but to part of the aortic valve as well. P.T.=pulmonary trunk; RPA.= right pulmonary artery. the left atrium was assumed to have been elevated in this patient.

The mean manifest electrical axis of the QRS complex lay between minus 70 and plus 100 degrees. The frontal QRS vectors obtained from the scalar electrocardiogram were directed clockwise in three (Cases 1, 2, and 5) and counterclockwise in three (Cases 3, 4, and 6). The main mass of the vector loop in the frontal plane lay above the zero line in one (Case 6) and a figure of eight loop was present in Case 4. Three patients gave electrocardiographic evidence of hypertrophy of the right ventricle. Two (Cases 1 and 2) showed a qR pattern in lead V6, the length of the $R$ wave being $10 \mathrm{~mm}$. in Case 1 and $22 \mathrm{~mm}$. in Case 2 . In these two patients the $S$ waves were deeper than the $R$ waves in lead V1.

Type II. In Type II each of the four patients also showed normal sinus rhythm. In all four the P-R interval was within normal limits and the mean manifest electrical axis of the QRS complex lay between plus 110 and 130 degrees. The vector loop in the frontal plane obtained from the scalar electrocardiogram was directed clockwise. Evidence for hypertrophy of the right ventricle was present in each case. Hypertrophy of the left ventricle was noted as well in two of those four patients (Cases 7 and 10). 


\section{Hemodynamic Features}

Catheterization of the right side of the heart had been performed in every case except Case 7 (anatomical Type IIA). The findings summarized in Table II will be considered here according to anatomical types and subtypes.

TABLE II

Hamodynamic Data in Nine Cases of Origin of Both Great Vessels from the Right Ventricle without Pulmonary STENosis

\begin{tabular}{|c|c|c|c|c|c|c|c|c|c|c|c|c|}
\hline \multirow{2}{*}{$\begin{array}{l}\text { Case } \\
\text { No. }\end{array}$} & \multirow{2}{*}{ Age } & \multicolumn{5}{|c|}{ Pressure $(\mathrm{mm} . \mathrm{Hg})$} & \multicolumn{5}{|c|}{ Oxygen saturation (per cent) } & \multirow{2}{*}{$\begin{array}{l}\text { Associated } \\
\text { anomalies }\end{array}$} \\
\hline & & RA & RV & PT & LV & SA & VC & RA & $\mathbf{R V}$ & PT & SA & \\
\hline
\end{tabular}

Type I

\begin{tabular}{|c|c|c|c|c|c|c|c|c|c|c|c|c|}
\hline 1 & $8 \mathrm{mo}$. & - & $100 / 0$ & - & - & - & $50 I$ & 59 & 69 & - & 92 & None \\
\hline \multirow{2}{*}{2} & $61 / 2$ yr.* & $20 / 10$ & $100 / 0$ & $95 / 57$ & - & - & - & - & - & - & - & \multirow{2}{*}{ None } \\
\hline & $121 / 3 \mathrm{yr}$. & $18 / 6$ & $125 / 25$ & - & $130 / 15$ & $125 / 80$ & $52 \mathrm{I}$ & 39 & 66 & - & $74 \ddagger$ & \\
\hline \multirow{3}{*}{3} & $101 / 4$ yr.* & $7 / 1$ & $94 / 0$ & $94 / 49$ & - & - & $67^{1} 57^{S}$ & 63 & 86 & 89 & 92 & \multirow{3}{*}{ None } \\
\hline & $19 \mathrm{yr}$. & $3+$ & $95 / 3$ & $108 / 54$ & - & - & $60 \mathrm{~s}$ & 66 & 91 & 90 & 96 & \\
\hline & $19 \mathrm{yr}$. & - & $130 / 0 \S$ & - & - & $130 / 75 \S$ & - & - & - & - & - & \\
\hline 4 & $11 / 2 \mathrm{mo}$ & $13 / 0$ & $84 / 10$ & - & - & - & $51^{1}$ & 50 & 71 & - & 92 & $\begin{array}{l}\text { Coarctation } \\
\text { of the aorta }\end{array}$ \\
\hline 5 & 3 mo.* & $7 / 3$ & $78 / 0$ & - & - & $74 / 64$ & $59 \mathrm{~S}$ & 62 & 74 & - & $92 \dagger$ & $\begin{array}{l}\text { Anomaly of } \\
\text { mitral valve }\end{array}$ \\
\hline \multirow{2}{*}{6} & $5 \mathrm{mo}$. & $12 / 4$ & $85 / 0$ & $85 / 50$ & - & - & $39146 \mathrm{~S}$ & 51 & 77 & 77 & 86 & \multirow{2}{*}{$\begin{array}{l}\text { Stenosing } \\
\text { ring of left } \\
\text { atrium }\end{array}$} \\
\hline & $2 \mathrm{yr}$. & - & $125 / 0$ & - & 一 & - & $43 I$ & 51 & 92 & - & 97 & \\
\hline
\end{tabular}

Type IIA

\begin{tabular}{c|c|c|c|c|c|c|c|c|c|c|c|c}
\hline $8 \ddagger$ & $12 \mathrm{mo}$. & $18 / 8$ & $120 / 0$ & - & $120 / 0$ & $115 / 75$ & - & 10 & 26 & - & 34 & $\begin{array}{c}\text { Coarctation } \\
\text { of the aorta }\end{array}$ \\
\hline 9 & $3 \mathrm{mo}$. & $7 / 3$ & $90 / 0$ & $60 / 20$ & - & $90 / 40$ & $43 \mathrm{I} 32^{\mathrm{S}}$ & 47 & $\begin{array}{l}92 \mathrm{Hi} \\
83 \mathrm{Lo}\end{array}$ & 92 & 85 & Normal \\
\hline
\end{tabular}

Type IIB

\begin{tabular}{c|c|c|c|c|c|c|c|c|c|c|c|c}
\hline \multirow{3}{*}{10} & $21 / 2 \mathrm{yr}$. & $6+$ & $104 / 27$ & $93 / 67$ & - & $100 / 72$ & $67 \mathrm{~S}$ & 57 & 62 & 77 & 76 & $\begin{array}{c}\text { Coarctation } \\
\text { of the aorta }\end{array}$ \\
\cline { 2 - 7 } & $41 / 2 \mathrm{yr}$. & - & $150 / 25$ & - & - & $140 / 800$ & - & - & - & - & 86 & \\
\hline
\end{tabular}

* Catheterization performed elsewhere; $+=$ mean pressure; $\dagger=$ Breathing 100 per cent oxygen; $\ddagger$ Patient studied under general anæsthesia and while in congestive cardiac failure; $R A=R$ ight atrium; $R V=R i g h t$ ventricle; PT $=$ Pulmonary trunk; $L V=6 /+$ ventricle; $\S=$ Values obtained during selective aortogram; o=Above coarctation; $\mathrm{I}=$ Inferior vena cava; $\mathrm{S}=$ Superior vena cava. 
Type I. Measurements revealed closely similar systolic pressures in the right ventricle and a systemic artery in each of the four patients for whom these values were recorded. Pulmonary arterial pressure was elevated in each of the four for whom it was measured and during systole it reached essentially the same level as the corresponding systolic pressure in the right ventricle.

- In five of the patients (Cases 1, 3, 4, 5, and 6) the oxygen saturation of the systemic arterial blood was 92 per cent or greater. The sixth (Case 2) manifested a greater degree of arterial desaturation $(74 \%)$ : cardiac catheterization, however, had been performed with the patient under general anæsthesia and during an episode of congestive cardiac failure. Clinically, the patient did not appear to be cyanotic. Oxygen saturation of the blood of the pulmonary trunk was lower than that for the blood in a systemic artery in the two patients in whom both values were determined. These findings suggest that in this type of malformation: (1) most of the blood in the aorta is derived from the left ventricle, and (2) mixing in the right ventricle is incomplete.

Type IIA. Two patients in this category (Case 8 and the one living patient, Case 9) had hæmodynamic values similar to those reported as occurring in the so-called Taussig-Bing complex. In both instances, marked desaturation was noted in the systemic peripheral arteries. The blood in the pulmonary trunk of one (Case 9) was found to have a significantly higher oxygen saturation than the blood of a systemic artery. Pressure relationships between the great arteries and the right ventricle were similar to those observed in Type I of the malformation.

Type IIB. In the one patient in this category (Case 10) the systolic pressures in the right ventricle, pulmonary trunk, and systemic artery were approximately equal. The degrees of oxygen saturation of the aortic blood and of the pulmonary arterial blood were almost identical ( 76 and $77 \%$, respectively). These physiological findings correlate well with the anatomical findings in this patient. The location of the defect in the ventricular septum below both pulmonary trunk and aorta would seem to allow equal access to both great vessels for oxygenated blood from the left ventricle.

The characteristic and distinctive physiological findings noted in each of the anatomical subgroups of the anomaly further justify such subdivisions. These hæmodynamic features appear to depend primarily upon the precise relationship of the ventricular septal defect to the aorta and to the pulmonary trunk. In interpreting the physiological data in this malformation, one must consider specific anatomical arrangements. An obligatory "shunt" of all blood from the left ventricle to the right ventricle occurs via the ventricular septal defect. Not all the arterialized blood reaching the right ventricle is "shunted" blood in the usual sense, for some of it is going to its normal goal, the aorta.

These considerations are particularly important in making a pre-operative evaluation of patients with this anomaly. For in them, peripheral cyanosis cannot be used as a poor prognostic sign, any more than calculated "high pulmonary blood flow" or "low pulmonary resistance" may be used as favourable prognostic indicators. We know of no dependable prognostic signs for assessing the possible advantages of surgical correction of this abnormality. Knowledge gained from the study of patients with ventricular septal defect indicates that early surgical correction would preclude development of obstructive pulmonary disease.

\section{RGENTGENOGRAPHIC FINDINGS}

In both major categories the conventional ræntgenographic findings were generally similar to those seen in cases of ventricular septal defect with pulmonary hypertension and left-to-right shunt. All patients had cardiomegaly, pulmonary plethora, and enlargement of the main pulmonary arteries (Fig. 9). In each patient in Type II the size of the pulmonary trunk was obviously large (Fig. 10). Re-study of selective angiocardiographic films from our cases leads us to certain conclusions.

Right ventriculography is helpful in establishing the diagnosis when the following features are observed. After injection of radio-opaque material both the aorta and the pulmonary trunk are filled. The aortic valve is found lying unusually high and at the same level as the pulmonary valve 


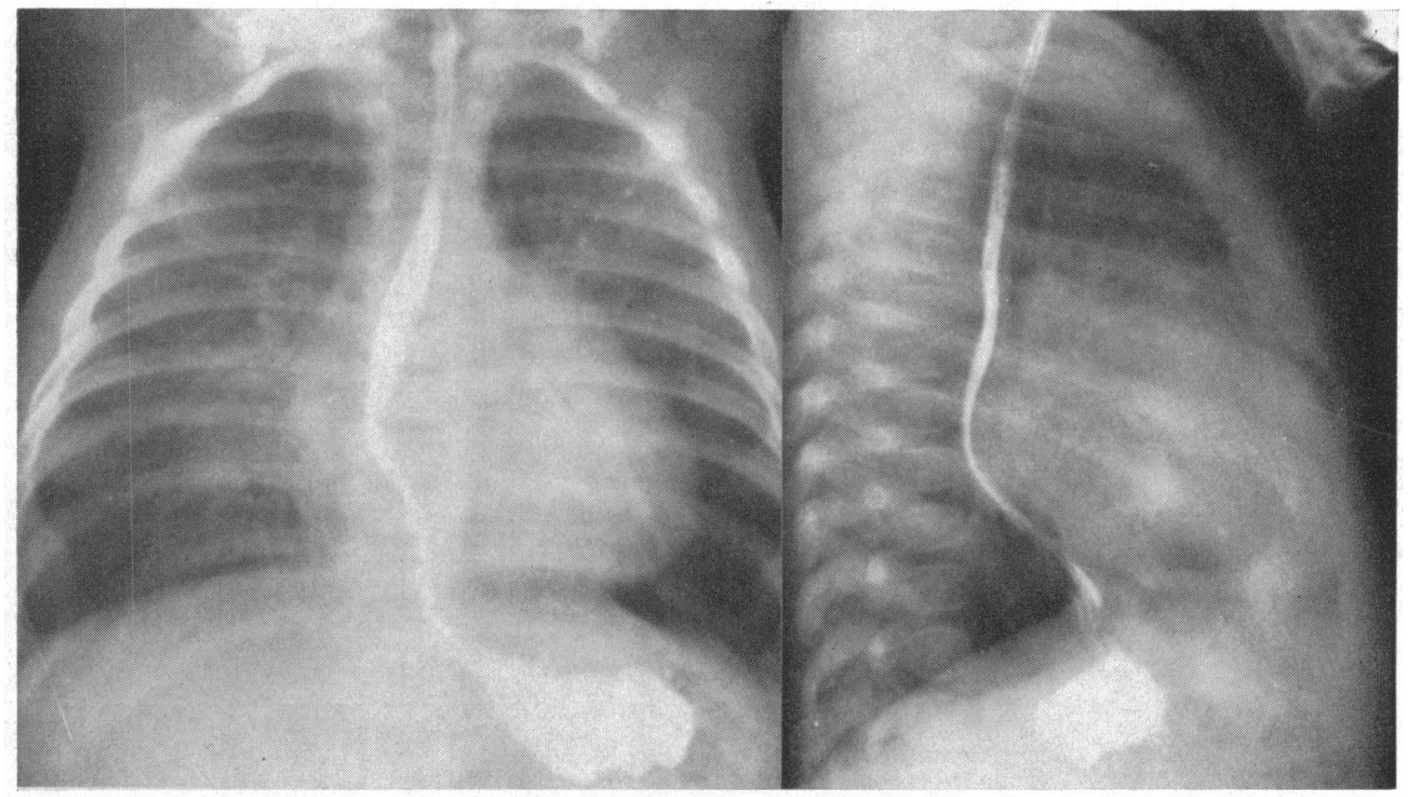

FIG. 9.-Case 5. Type I, Left: Conventional rœntgenogram, frontal view. Moderate cardiomegaly with increased pulmonary arterial vasculature. The pulmonary trunk is much enlarged. The oesophagus is deviated to the right as a result of left atrial enlargement. Right: Lateral view from the same patient. The left atrial enlargement is prominent. In this patient in addition to the origin of both great vessels from the right ventricle without pulmonary stenosis, Type I, the necropsy revealed evidence of mitral insufficiency (see Fig. 5).

(Fig. 11). In Type II, injection of opaque material into the right ventricle will cause the aorta to appear more dense than does the pulmonary artery, whereas in Type I the pulmonary artery will be more dense than the aorta (Fig. 12). Selective aortography, while not definitively diagnostic, may lead to a presumptive diagnosis if (1) the position of the aortic valve is found to be unusually high and (2) the ascending aorta runs near the vertical, rather than turning toward the left ventricle as it does in the normal subject and in the ordinary variety of ventricular septal defect.

By allowing visualization of the channel leading from left ventricle to one or the other of the great vessels (Fig. 13), left ventriculography may offer additional help in determining the position of the ventricular septal defect in its relation to the crista supraventricularis.

\section{COMMENT}

Origin of both great vessels from the right ventricle without pulmonary stenosis is apparently an uncommon malformation. Pathological reports have been made for only a few cases during the last 25 years and for relatively fewer in the past century. Only recently has the clinical syndrome been described and the importance of clinical diagnosis been emphasized.

The original communication of Taussig and Bing describing an anatomical entity now known as the Taussig-Bing complex, contained no photographic reproduction of the specimen but only a drawing. This illustration suggests that the ventricular septal defect lay immediately beneath the pulmonary valve and above the crista supraventricularis, while the aortic valve lay to the right of and at the same level as the pulmonary valve. In the case mentioned, not only were the anatomical findings similar to those that we have found in the condition designated here as origin of both great vessels from the right ventricle, Type IIA, but also the clinical findings were similar to those in our three cases of this anomaly. We are therefore of the opinion that it is proper to 


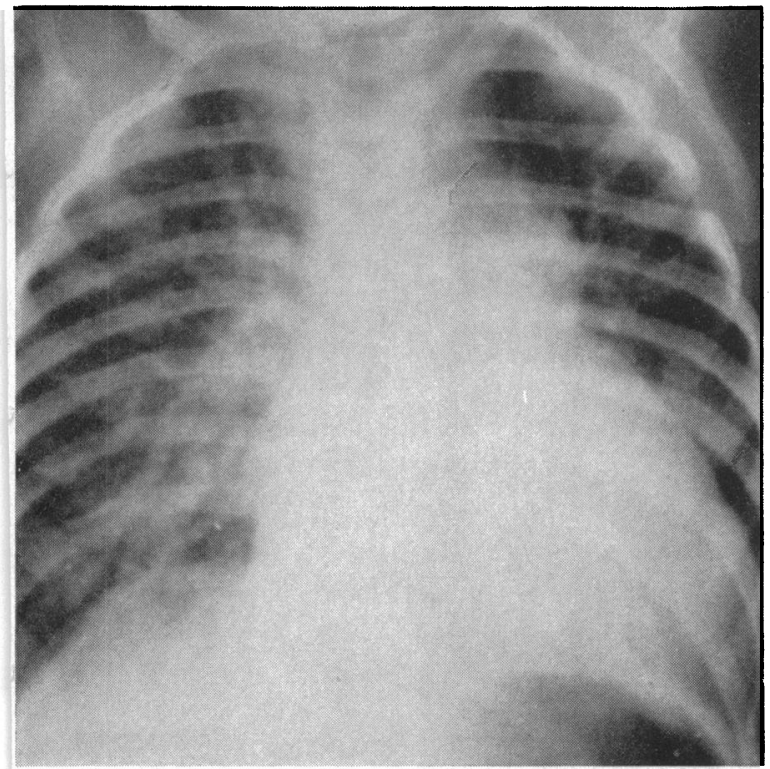

FIG. 10.-Case 9. Type IIA. Conventional ræntgenogram, frontal view. Conspicuous cardiomegaly associated with enlargement of the pulmonary trunk. The pulmonary arterial vasculature is increased.

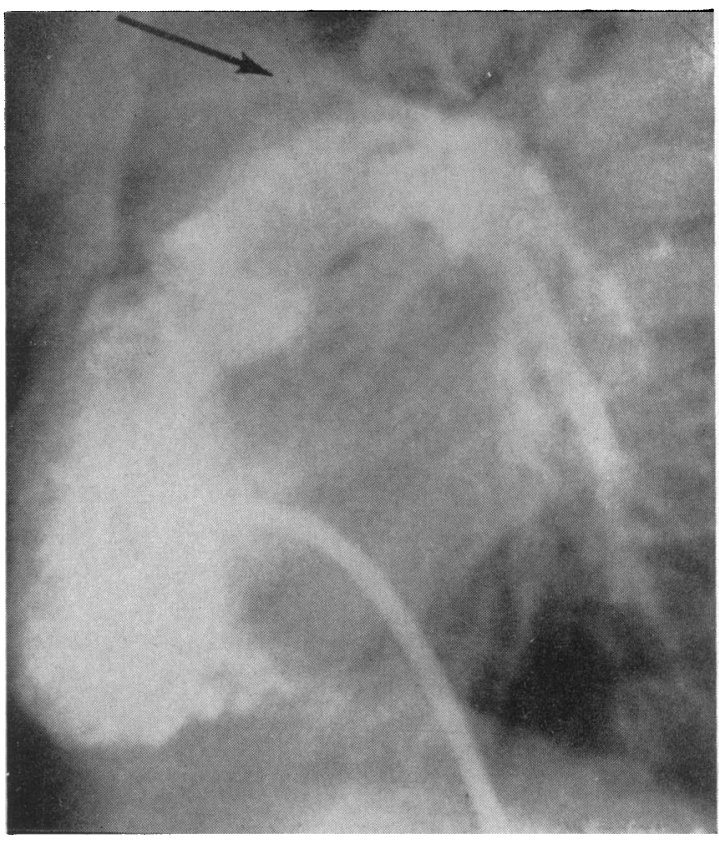

FIG. 11.-Case. 5. Type I. Lateral view of selective right ventriculogram. The right ventricle is densely opacified. Following opacification of the right ventricle, the pulmonary valve and pulmonary trunk are visualized. The ascending aorta (arrow) is faintly opacified.

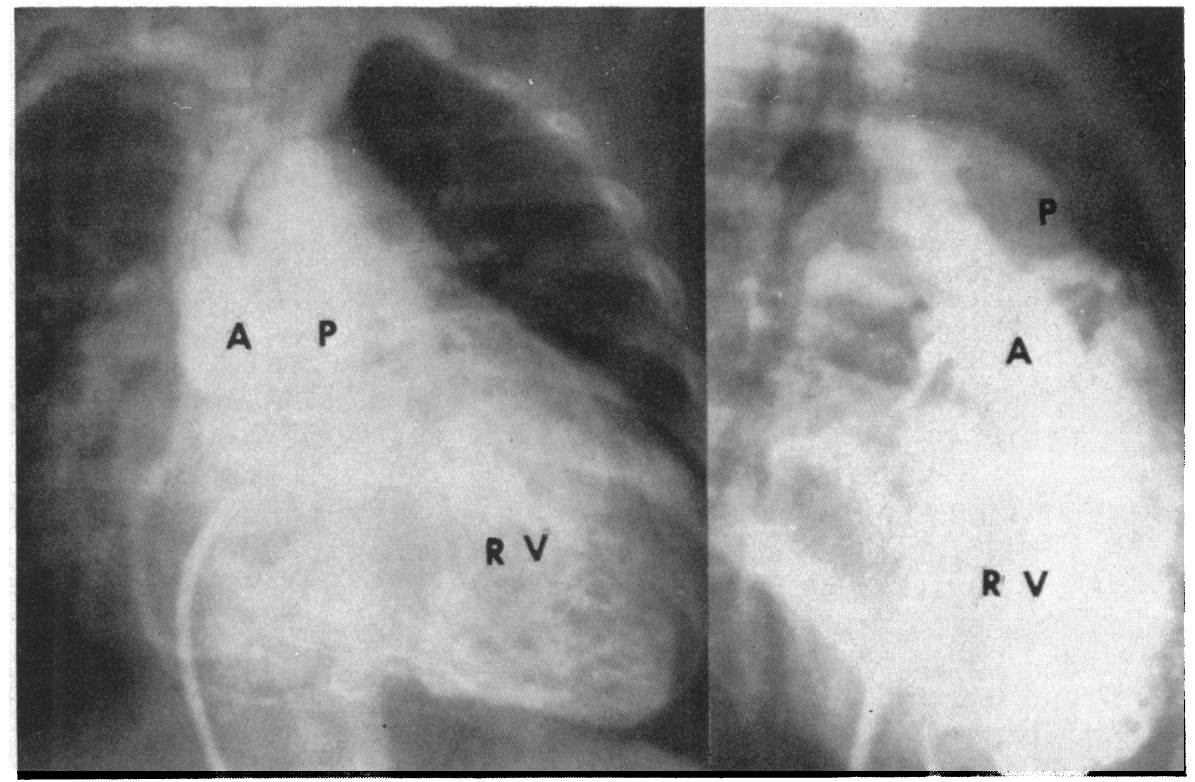

Fig. 12.-Case 8. Type IIA. Left: Frontal view of selective right ventriculogram. The right ventricle (RV) is opacified as are the ascending aorta (A) and the pulmonary trunk (P). Right: Lateral view of selective right ventriculogram. The right ventricle and the ascending aorta and pulmonary trunk are opacified. Note that the ascending aorta is more densely opacified than the pulmonary trunk. 


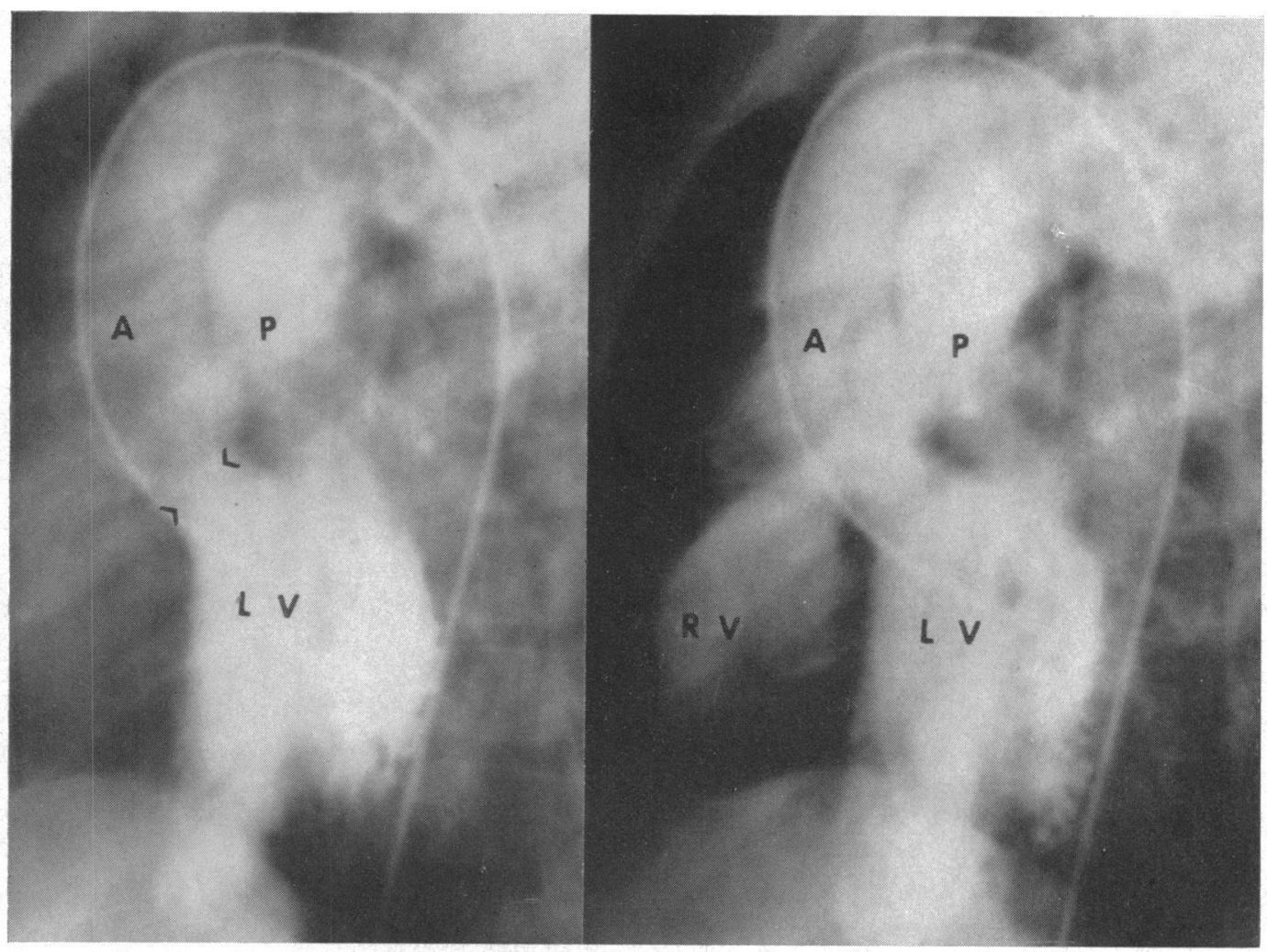

FIG. 13.-Case 10. Type IIB. Selective left ventriculogram, lateral view. Left: The left ventricle (LV) is opacified. After opacification of the left ventricle a portion of the right ventricle is opacified through the ventricular septal defect (arrows). Both the ascending aorta (A) and the pulmonary trunk (P) are opacified. The ascending aorta lies anteriorly to the pulmonary trunk. Right: A later stage than in Left. At this time, more radio-opaque material has entered the right ventricle (RV).

bring the Taussig-Bing complex into the broad category of origin of both great vessels from the right ventricle, bearing in mind that within this group there are important anatomical, functional, clinical, and therapeutic differences.

The material presented here suggests that in the group of cases classified as representing Type I, the clinical problem resembles that in large ventricular septal defect with a dominant left-to-right shunt. In the cases considered to be instances of Type II, the dominant picture is that of a right-toleft shunt associated with pulmonary hypertension.

What appear to be the controlling factors in directing blood from the left ventricle predominantly to the aorta and blood from the right ventricle to the pulmonary trunk in the Type I anomaly? Why in Type II, and especially Type IIA, is a greater proportion of the output of the left ventricle directed to the pulmonary artery than to the aorta?

In a circulatory system with a large ventricular septal defect, the dominant factor determining the direction of shunt is the relationship in resistances to blood flow between the pulmonary vascular system on one hand and the systemic system on the other. While, as has been explained, in origin of both great vessels from the right ventricle, measurement of vascular resistances are unreliable, one may gain some idea of the level of pulmonary vascular resistance from histological examination of the pulmonary vessels. In our material, even in instances of the Type IIA anomaly, cyanosis and arterial oxygen desaturation occurred when the pulmonary vessels showed no intimal disease, a 
feature associated only with left-to-right shunt in ordinary large ventricular septal defect. This suggests that in these cases some factor other than relative resistance operates to influence predominant direction of blood flow. Additional support for such a premise is derived from the fact that in the Type IIA anomaly the level of oxygen saturation of the pulmonary arterial blood is higher than that of the aortic blood; this pattern of saturation is the reverse of that in the Type I anomaly.

The foregoing suggests that although relative vascular resistances may play some part in governing direction and volume of blood flow from the ventricles, a determining factor in origin of both great vessels from the right ventricle is the position of the ventricular septal defect. This anatomical factor in turn appears to dictate the directions that the left ventricular and right ventricular streams will tend to take.

The Type I anomaly, in which the ventricular septal defect lies below the crista supraventricularis and is remote from the pulmonary valve, is characterized by the following pattern. Blood from the left ventricle passing through the ventricular septal defect is predominantly directed to the more closely related aortic valve, while the right ventricular stream crosses the left and is predominantly directed toward the pulmonary valve.

On the other hand, in the Type IIA anomaly, in which the ventricular septal defect lies above the crista supraventricularis and is intimately related to the pulmonary valve, the two ventricular streams tend not to cross. The stream of blood coming from the left ventricle is directed primarily toward the pulmonary valve. Moreover, this stream tends to direct blood coming from the right ventricle away from the pulmonary valve and toward the aorta. Support for this streaming theory is given by the data obtained in our Case 10, an example of the Type IIB anomaly in which the ventricular septal defect lay directly under both the aortic and pulmonary valves. In this case the levels of oxygen in the blood of both great vessels were about equal. Applying the classification presented here to the eight cases of origin of both great vessels from the right ventricle without pulmonary stenosis described in an earlier communication by Neufeld et al. (1961), one finds that seven of these manifested the features of Type I and the eighth (their Case 4) showed pathological, functional, and clinical features of Type IIA.

\section{SUMMARY}

Clinical, hæmodynamic, rœntgenographic, and anatomical findings are presented for ten patients with origin of both great vessels from the right ventricle without pulmonary stenosis. A new classification into two main types is offered, based on the anatomical position of the ventricular septal defect.

The sub-group in which the ventricular septal defect lies below the crista supraventricularis is designated as Type I, that in which the defect lies above the crista supraventricularis as Type II.

In each case in both types, the ventricular septal defect constituted the only outlet for the left ventricle. In all patients the aortic and pulmonary valves lay in approximately the same crosssectional and coronal body planes. Usually, the mitral valve did not show continuity with the aortic valve. In Type I, these valves might occasionally be continuous because of an unusual long anterior leaflet on the mitral valve.

The clinical features in Type I simulated those in cases of large ventricular septal defect associated with pulmonary hypertension.

The electrocardiographic findings differed strikingly from Type I to Type II. In patients of Type I the mean manifest electrical axis ranged from plus 60 degrees to minus 70 degrees, the vector loop in the frontal plane being directed counterclockwise in four of the six patients. In patients of Type II the QRS axis was between plus 110 and plus 130 degrees.

Electrocardiographic findings of a counterclockwise loop in the frontal plane in the presence of clinical and laboratory findings like those in ventricular septal defect with marked pulmonary hypertension should arouse the suspicion of origin of both great vessels from the right ventricle without pulmonary stenosis, Type I. 
Selective angiocardiography and aortography are particularly important in establishing the diagnosis. Since the surgical approach employed in this malformation differs from that followed in the usual ventricular septal defect, the importance of distinguishing these two anomalies is obvious.

Patients with the Type II malformation presented a picture of cyanotic congenital heart disease associated with increased pulmonary arterial flow. The position of the defect in this type enables oxygenated blood from the left ventricle to enter directly into the pulmonary artery and is therefore responsible for the different hæmodynamic and clinical findings as compared to Type I. Selective angiocardiography and hæmodynamic studies are strongly recommended for establishing a clinical diagnosis of origin of both great vessels from the right ventricle without pulmonary stenosis Type II and for distinguishing Types I and II.

While a curative surgical procedure is available for the Type I malformation, none has yet been established for Type II.

\section{REFERENCES}

Neufeld, H. N., DuShane, J. W., Wood, E. H., Kirklin, J. W., and Edwards, J. E. (1961). Circulation, 23, 399. Taussig, H. B., and Bing, R. J. (1949). Amer. Heart J., 37, 551.

Manubens, R., Krovetz, L. J., and Adams, P., Jr. (1960). Amer. Heart J., 60, 286. 